
ANTI-PAPILLOMA ACTIVITY

\author{
Jiangning Wang*, Xiaorong Li, Lei Gao, \\ Central Laboratory, Luhe Teaching Hospital of the Capital Medical University, \\ Beijing, 101100, China, \\ *E-mail: wangjiangning135@163.com
}

\begin{abstract}
The objective of this paper was to study the extraction methods of tannin constituents from Semen Cuscutae and their anti-papilloma effects. Single factor test and orthogonal design methods were used to determine the optimal extraction method; the mouse skin papilloma model induced by DMBA/croton oil was established, which was a classic two-stage carcinogenesis model being used to observe and evaluate the anti-carcinogenic effects of tannins extracted from Semen Cuscutae in different stages. The optimal extraction method of Semen Cuscutae was a 20-fold volume of solvent, a temperature of $50{ }^{\circ} \mathrm{C}$, three times of extraction, with $20 \mathrm{~min}$ each, skin papilloma experiment revealed that the number of bearing tumors gradually reduced, and the inhibition rate gradually increased with the increase of dose, in the high-dose group, its inhibition rate reached $70.2 \%$. Tannin extract from Semen Cuscutae has an obvious inhibitory effect on skin papilloma development.
\end{abstract}

Keywords: Semen Cuscutae; tannin; skin papilloma

\title{
Introduction
}

Semen Cuscutae is the dried mature seeds of Cuscuta chinensis Lam. in the Convolvulaceae family, which is also called Longxuzi, Tusizi, etc and bought from Anguo Ltc. in Henan. It is mainly distributed in Liaoning, Jilin, and Hebei of China. It is sweet in taste, neutral in nature, and has the effects of nourishing liver and kidney, securing essence and reducing urination, preventing miscarriage, improving eyesight, and arresting bleeding. Its main chemical constituents are flavonoids, lignans, and steroidal compounds (Lin et al., 2009; Ye et al., 2001). Its pharmacological effects are mainly manifested in the reproductive system, immune system, anti-oxidation, and anti-mutation aspects. Clinically, it is commonly used in the prevention and treatment of cardiovascular diseases, protection of liver, improvement of eyesight, and enhancement of immunity (Wu et al., 2009; Li et al., 2009; Song et al., 2010; Liu et al., 2004).

Cancer has become a common and frequently-occurring disease seriously harming human health, which is a major disease causing death of human beings. In the early stage of cancer, tumor is small, not metastasized or metastasizes single unobvious symptom which is easily ignored. In the advanced stage, tissue infiltration occurs around the lesion, most of which is accompanied by metastasis, and corresponding complications. Mouse experimental model of skin papilloma genesis is the most intuitive, first choice model for the study of anti-carcinogenic effect of drugs, the advantage of the model is that the skin papilloma can be quantitated with naked eyes. Literatures have reported that the good curative effect of water extract of Semen Cuscutae on skin papilloma, but the specific extraction process is not yet standardized. In this experiment, the extraction process of Semen Cuscutae and its anti-papilloma effect were studied, laying the foundation for future clinical use of the drug.

\section{Materials and Methods Drugs}

Semen Cuscutae was bought from Anguo Ltc. And the number of the specimen was 20110321. It was stored in room 105 in School of Pharmacy of Dalian Medical University.

\section{Reagents}

Gallic acid (Wenzhou Ouhai Fine Chemicals Corporation, Zhejiang); anhydrous sodium carbonate (Tianjin Bodi Chemical Holding Co., Ltd.); sodium phosphate (Sinopharm Chemical Reagent Co., Ltd.); DMBA (Fluka); croton oil (Jiangxi Huabao Natural Medicinal Medicinal Oil Refinery)

\section{Instruments}

UV-2100 UV-visible spectrophotometer (UNICO Instruments Co., Ltd.); HH-8 digital thermostat water bath (Guohua Electric Appliance Co., Ltd.); FA1004 analytical balance (Shanghai Jingke Balance)

Experimental animals 


\section{http://dx.doi.org/10.4314/aitcam.v10i3.13}

Kunming mice, weighing 18 22 g, half male and half female, were provided by the Laboratory Animal Center of China Medical University.

Method for determination of tannins (Chinese Pharmacopoeia Commission., 2010) Preparation of reference solution

$50 \mathrm{mg}$ of gallic acid reference substance was accurately weighed and placed in a $100 \mathrm{ml}$ brown volumetric flask, dissolved in water and diluted to the mark, then precise amount of $5 \mathrm{ml}$ of the solution was taken and placed in a $50 \mathrm{ml}$ brown volumetric flask, diluted to the mark with water, shaken well, and reserved for later use (concentration of $0.05 \mathrm{mg} / \mathrm{ml}$ ).

\section{Preparation of standard solution}

The precise amounts of $0.5,1.0,2.0,3.0,4.0,5.0 \mathrm{ml}$ of the reference solution were weighed and placed in 25 $\mathrm{ml}$ brown volumetric flasks respectively, each added with $1 \mathrm{ml}$ of phosphomolybdotungstic acid reagent, plus $11.5,11,10$, $9,8,7 \mathrm{ml}$ of water, and diluted to the mark with $29 \%$ sodium carbonate solution, shaken well, and allowed to stand for $30 \mathrm{~min}$, absorbance value was measured at $760 \mathrm{~nm}$ wavelength with the corresponding reagent as the blank, and standard curve was drawn with absorbance as the ordinate, and the concentration as the abscissa. $\mathrm{Y}=0.1582 \mathrm{X}+0.0793, \mathrm{R}^{2}=0.9931$.

\section{Preprocessing of crude drug}

$5 \mathrm{~g}$ of Semen Cuscutae powder was added to $150 \mathrm{ml}$ of water and ultrasonically extracted twice, each extraction lasted for $50 \mathrm{~min}, 105^{\circ} \mathrm{C} 2 \mathrm{~h}$, and the extract was obtained.

\section{Determination method}

Total phenols: The precise amount of $2 \mathrm{ml}$ of the test sample was weighed and placed in a $25 \mathrm{ml}$ brown volumetric flask, as the method described above, $1 \mathrm{ml}$ of phosphomolybdotungstic acid reagent plus $10 \mathrm{ml}$ of water were added, and absorbance value was measured according to the method 2.1.2, the amount of gallic acid in test sample was then read from the standard curve.

Unabsorbed polyphenols: The precise amount of $25 \mathrm{ml}$ of sample solution was weighed and added to a volumetric flask containing $100 \mathrm{ml}$ of with the concentration of $6 \mathrm{mg} / \mathrm{ml}$, warmed in a $30^{\circ} \mathrm{C}$ water bath for $1 \mathrm{~h}$, oscillated from time to time, taken out, let cool, shaken well, and filtrated, then precise amount of $2 \mathrm{ml}$ of filtrate was weighted and added to a 25 $\mathrm{ml}$ brown volumetric flask, and the amount of gallic acid was calculated in accordance with the method 2.1.2,

Tannin content was calculated according to the following formula:

Tannin content $=$ total phenol content - unabsorbed polyphenol content

\section{Investigation of extraction process Single factor investigation}

Selection of extraction method: two portions of $5 \mathrm{~g}$ of Semen Cuscutae powders were added with $200 \mathrm{ml}$ of water, one was extracted in a $70{ }^{\circ} \mathrm{C}$ water bath for $1 \mathrm{~h}$, and the other ultrasonically extracted at $70^{\circ} \mathrm{C}$ for 15 min, followed by vacuum suction filtration, then water was added to the filtrate until the volume reached $200 \mathrm{ml}$.

Effect of ultrasonic time on yield: $5 \mathrm{~g}$ of Semen Cuscutae powder was taken and added with $200 \mathrm{ml}$ of water, and extracted at $70{ }^{\circ} \mathrm{C}$ for $20,30,40,50,60$ min respectively, then suction filtered, added with water to make the volume $200 \mathrm{ml}$, and yield was determined.

Effect of extraction temperature on yield: $5 \mathrm{~g}$ of Semen Cuscutae powder was taken and added with $200 \mathrm{ml}$ of water, and extracted at $50,60,70,80,90{ }^{\circ} \mathrm{C}$ for $15 \mathrm{~min}$ respectively, then suction filtered, added with water to make the volume $200 \mathrm{ml}$, and yield was determined.

Effect of solid-liquid ratio on yield: $5 \mathrm{~g}$ of Semen Cuscutae powder was taken and added with 25, 50, 100, 150, 200 $\mathrm{ml}$ of water respectively, and extracted at $70{ }^{\circ} \mathrm{C}$ for $15 \mathrm{~min}$, then suction filtered, concentrated by rotary evaporation, added with water to make the volume $200 \mathrm{ml}$, and yield was determined.

\section{Orthogonal test}

Based on the ultrasonic single factor experiment, three levels were taken from the variation curve of single factor experiment, $\mathbf{L}_{9}\left(3^{4}\right)$ orthogonal analysis was performed and optimal extraction process was obtained.

\section{Method for induction of mouse two-stage skin papilloma}

100 mice were randomly divided into five groups, namely the model group, dose groups (drug concentrations were $100,200,300 \mathrm{mg} / \mathrm{kg}$ for high-, medium-, low-dose groups respectively), and positive control group (tretinoin), each group contained 20 mice. 3 days before the experiment, back hair was carefully removed from mouse with $8 \%$ sodium sulfide. On the 1st, 7th, and 14th day of the experiment, DMBA/acetone $(150 \mu \mathrm{g} / 200 \mu \mathrm{l})$ was smeared on the depilated skin to induce cancer, which was a total of three times. From the 5th week, $0.25 \%$ croton oil $(200 \mu l)$ was smeared on the same site twice a week to promote the occurrence of cancer, until the end of the experiment. From the 1st day of the experiment, experimental animals were intragastrically administered the Semen Cuscutae, positive drug, and negative drug (normal saline) 


\section{http://dx.doi.org/10.4314/ajtcam.v10i3.13}

by group once every two days, the experiment lasted for 12 weeks. During the experiment, changes in papilloma on the dorsum of the mice were observed, and the number of tumor-bearing mice and the number of bearing-tumors in each mouse were recorded. Tumor incidence rate, average number of bearing-tumors per mouse and tumor inhibition rate were calculated according to the following formulas.

Tumor incidence rate $\%=$ number of tumor-bearing animals in each group / number of surviving animals in that group $\times 100$

Average number of bearing-tumors per mouse $=$ Total number of papilloma genesis in each group / number of surviving mice in that group

Inhibition rate $\%=$ (average number of tumors of model group - average number of tumors of dose group) / average number of tumors of model group $\times 100$

Table 1: Factors and levels table

\begin{tabular}{|c|c|c|c|c|}
\hline Level & $\begin{array}{l}\text { Factor } \\
\text { A }\end{array}$ & B & $\mathrm{C}$ & $\mathrm{D}$ \\
\hline 1 & $\begin{array}{l}\begin{array}{l}\text { Amount of water addition } \\
\text { (fold) } \\
10\end{array} \\
\end{array}$ & $\begin{array}{l}\text { Extraction } \\
\text { time (min) } \\
20\end{array}$ & $\begin{array}{l}\text { Extraction frequency } \\
\text { (number of times) } \\
1\end{array}$ & $\begin{array}{l}\text { Extraction } \\
\text { temperature }\left({ }^{\circ} \mathrm{C}\right) \\
50\end{array}$ \\
\hline 2 & 20 & 30 & 2 & 60 \\
\hline 3 & 30 & 40 & 3 & 70 \\
\hline
\end{tabular}

\section{Results}

Results of single-factor test

Selection of extraction method

Heat reflux extraction and ultrasonic extraction were selected in this experiment, it can be seen from the figure that the amount of total tannins obtained by ultrasonic extraction was higher than that by heat reflux extraction method, and therefore, ultrasonic extraction method was used in the present test, as shown in Figure 1.

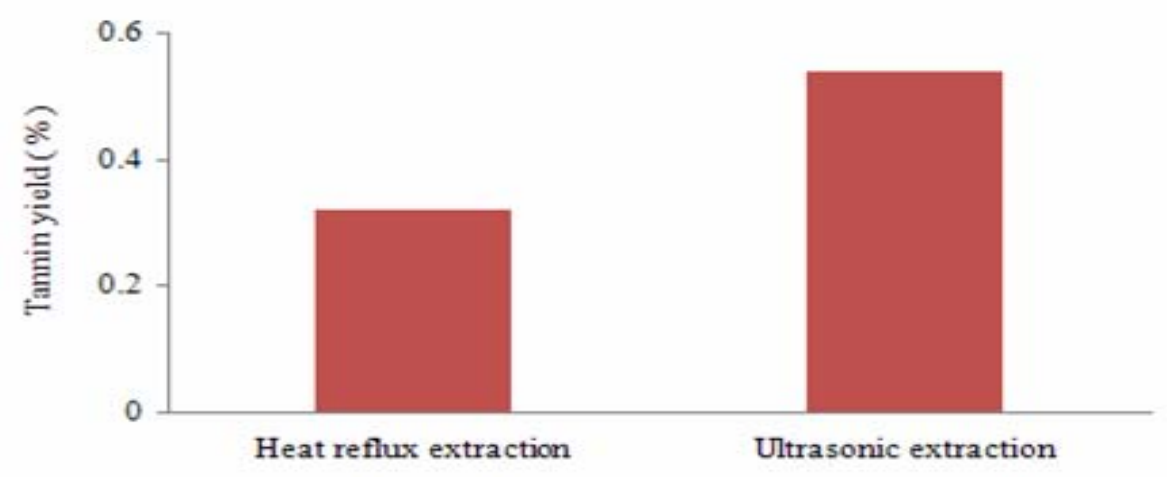

Figure 1: Selection of extraction method

\section{Effect of ultrasonic time on yield}

Samples that were ultrasonically extracted for 20, 30, 40, 50, 60 min were measured for yield respectively, it can be seen from the figure that, the yield of total tannins rose faster when the extraction time was between $20 \sim 40$ min, after that, increase in yield was not observed with the extension of time, therefore, $40 \mathrm{~min}$ was selected as the extraction time, as shown in Figure 2 


\section{http://dx.doi.org/10.4314/ajtcam.v10i3.13}

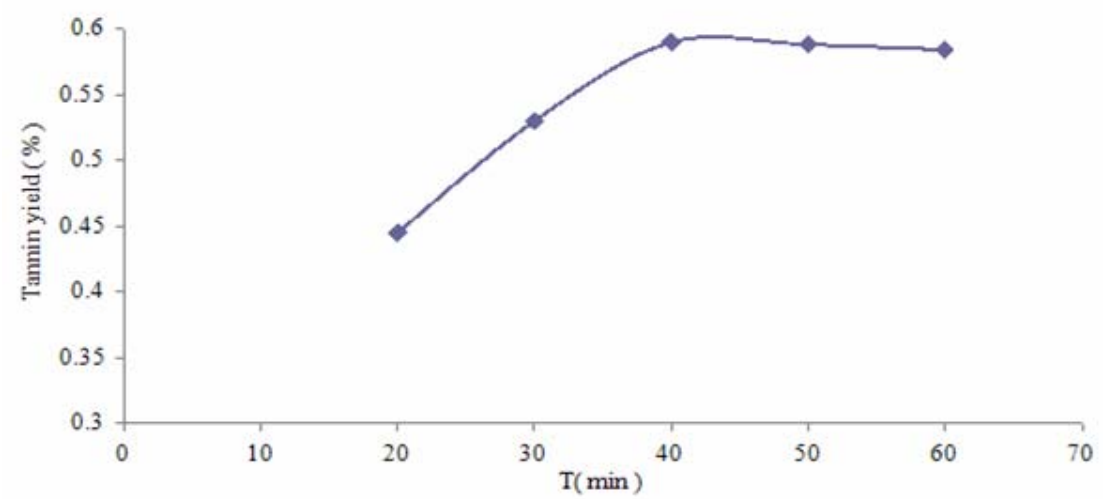

Figure 2: Extraction time

\section{Effect of extraction temperature on yield}

Samples that were ultrasonically extracted at 50,60, 70, 80, 90 were measured for yield respectively, it can be seen from the figure that, the yield of total tannins increased faster when temperature was around $50 \sim 70^{\circ} \mathrm{C}$, after that, the yield of total tannins slightly decreased with the increase of temperature, so 70 was selected as the optimal extraction temperature, as shown in Figure 3

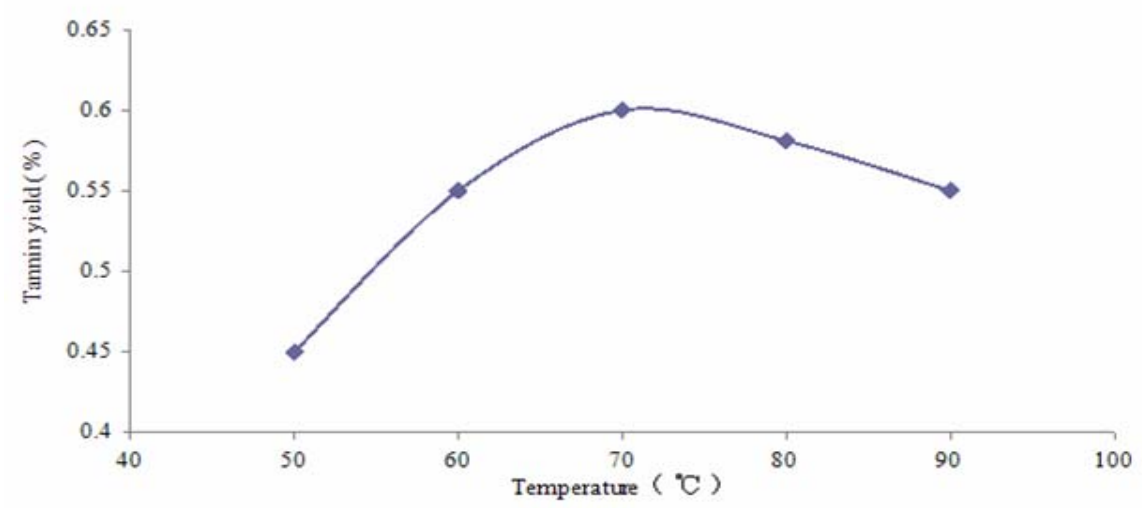

Figure 3: Extraction temperature

\section{Effect of solid-liquid ratio on yield}

Samples that were added with $25,50,100,150,200 \mathrm{ml}$ of solvents were ultrasonically extracted, the results are shown in the figure, the yield of total tannins increased significantly when the volume of solvent was $25 \sim 150 \mathrm{ml}$, there was no significant change in yield when the solvent volume was $150 \sim 200 \mathrm{ml}$, indicating that $5 \sim 30$ folds of water was the wateraddition range in the present experiment, as shown in Figure 4.

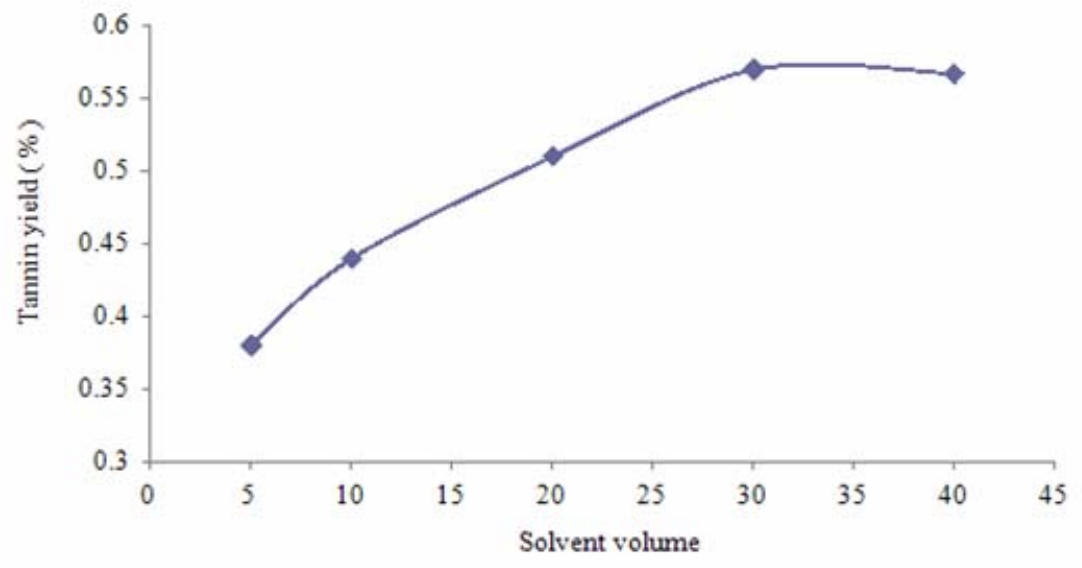

Figure 4: Solvent volume 


\section{http://dx.doi.org/10.4314/ajtcam.v10i3.13}

\section{Orthogonal test}

Table 2: Intuitive analysis results of orthogonal test

\begin{tabular}{llllll}
\hline Test No. & $\begin{array}{l}\text { Amount of water } \\
\text { addition }\end{array}$ & $\begin{array}{l}\text { Extraction time } \\
\text { B }\end{array}$ & $\begin{array}{l}\text { Extraction } \\
\text { frequency } \\
\text { C }\end{array}$ & $\begin{array}{l}\text { Extraction } \\
\text { temperature } \\
\text { D }\end{array}$ & $\begin{array}{l}\text { Tannin content } \\
(\mathrm{mg} / \mathrm{g})\end{array}$ \\
\hline 1 & 1 & 1 & 1 & 1 & 3.465 \\
2 & 1 & 2 & 2 & 2 & 3.523 \\
3 & 1 & 3 & 3 & 3 & 2.716 \\
4 & 2 & 1 & 2 & 3 & 3.439 \\
5 & 2 & 2 & 3 & 1 & 4.261 \\
6 & 2 & 3 & 1 & 2 & 3.017 \\
7 & 3 & 1 & 3 & 2 & 2.595 \\
8 & 3 & 2 & 1 & 3 & 3.271 \\
9 & 3 & 3 & 2 & 1 & \\
$\mathrm{~K} 1$ & 3.235 & 3.500 & 3.037 & 3.666 & \\
$\mathrm{~K} 2$ & 3.572 & 3.471 & 3.411 & 3.378 & \\
$\mathrm{~K} 3$ & 3.165 & 3.001 & 3.524 & 2.928 & \\
$\mathrm{R}$ & 0.407 & 0.499 & 0.487 & 0.738 & \\
\hline
\end{tabular}

The intuitive analysis results showed that the optimal extraction method of tannins from Semen Cuscutae is $A_{2} B_{1} C_{3} D_{1}$, that is, a 20-fold volume of solvent, a temperature of 50 , there times of extraction, with 20 min each.

Table 3: Variance analysis results of orthogonal test

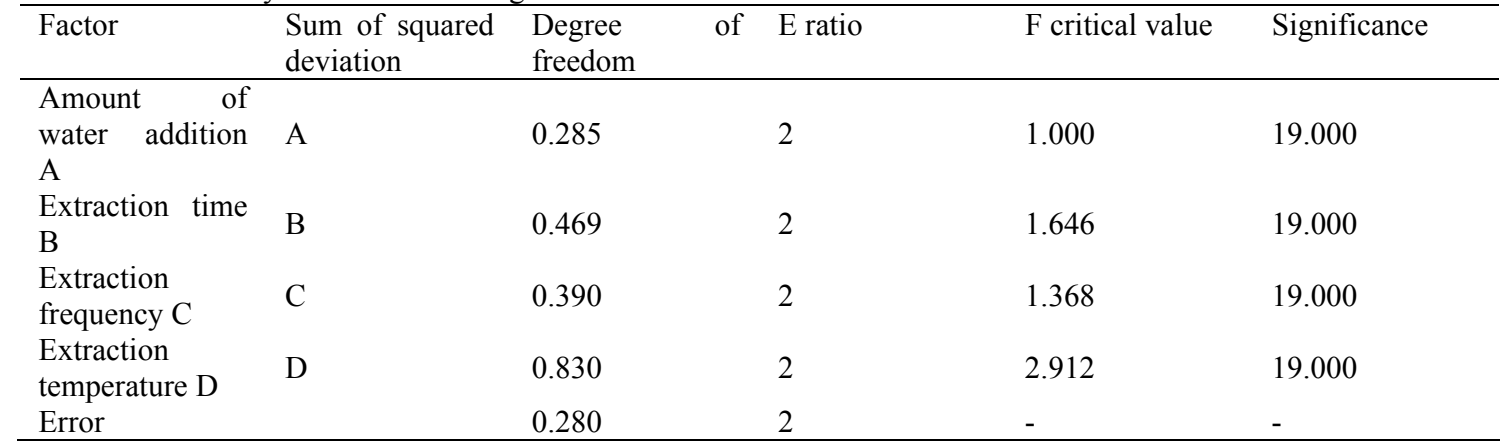

As can be seen from the analysis of variance, there was no significant difference, and therefore intuitive analysis was referenced to determine the optimal extraction process.

\section{Mouse skin papilloma}

From the 5th week, papilloma began to appear in the negative control group, and number of induced tumors and number of bearing tumors per mouse gradually increased with the passage of time. In the drug groups, papilloma began to appear in the 6th 7 th week, time of incidence was delayed and number of tumors was reduced when compared with the negative control group, which were in a dose-dependent manner, with the increase of does, the number of bearing tumors gradually reduced, and inhibition rate gradually increased. The results are shown in Table 4.

Table 4: Mouse skin papilloma results

\begin{tabular}{llllll}
\hline Group & $\begin{array}{l}\text { Number } \\
\text { animals }\end{array}$ & of & Tumor incidence rate (\%) & $\begin{array}{l}\text { Average } \\
\text { bearing-tumors/mouse }\end{array}$ & $\begin{array}{l}\text { of } \\
\text { rate (\%) }\end{array}$ \\
\hline Negative control & 20 & 90 & 74 & - \\
High-dose & 20 & 85 & 23 & 70.2 \\
Medium-dose & 20 & 80 & 35 & 59.3 \\
Low-dose & 20 & 70 & 58 & 36.5 \\
Positive control & 20 & 75 & 15 & 83.6 \\
\hline
\end{tabular}

\section{Discussion}

Mouse two-stage skin papilloma model is one of the commonly used models in the evaluation of anti-cancer chemopreventive action of compounds. M. Nisa et al had found that the effect of a hot water extract of C. chinensis on DNBA induced skin papilloma was satisfying (M. Nisa et al., 1986). Besides the water extracts, other organic reagents extracts also have more bioactivities. For example, n-butanol and methanol extracts of SC significantly suppressed LPS- 


\section{http://dx.doi.org/10.4314/ajtcam.v10i3.13}

stimulated DC activation, and kaempferol was identified as the major flavonoid in the methanol fraction of SC (Lin et al., 2011). In this experiment, the tannin extract from Semen Cuscutae exhibited certain inhibitory effect on skin papilloma, the number of bearing tumors in each mouse significantly reduced, and tumor ncidence was reduced, which indicated the tumor chemopreventive effect of the extract. Furthermore, Semen Cuscutae is both medicinal and edible, and literatures (Wang et al., 2003; Zhang et al., 2009; Zhang et al., 2012; Xia et al., 2012) have reported that it has a wide range of pharmacological effects such as anti-oxidation, anti-aging, etc., and therefore it has a potential development prospect.

\section{References}

1. Chinese Pharmacopoeia Commission. (2010). Pharmacopoeia of the People's Republic of China, Volume 1. China.Med.Sci.Press, Appendix 62.

2. Li, J.P., Wang, J., Zhang, Y.W., et al. (2009). Research progress on Cuscuta chinensis Lam. China.Med.Herald, 6 (23): 4-6.

3. Lin, Q., Jia, L.Y., Sun Q.S. (2009). Chemical constituents of the seeds of Cuscuta chinensis Lam. J.Shenyang.Pharmaceutical.Univer., 26 (12): 968-971.

4. Liu,Z.R., Luo,P.T., Fu,T.J., Ji,Y.Q. (2004). Wang,R.Z. The cardiovascular activities of Dodder extracts by three different extraction process. (6): 532-534.

5. Lin, M.K., Yu, Y.L., Chen, K.C. et al. (2011). Kaempferol from Semen cuscutae attenuates the immune function of dendritic cells. Immunobiology, 216, (10):1103-1109.

6. M. Nisa, S. Akbar, M. Tariq and Z. Hussainl. (1986). Effect OF CUSCUTA CHINENSIS water extract on 7,12dimethylbenz[a]anthracene-induced skin papillomas and carcinomas in mice. Journal of Ethnopharmacology, 18: 2131.

7. Song,M., Li,S.M., Chai,L.Q. (2010). Dodder flavonoids and its protective role of water decoction. Jiangsu.Agricult.Sci., (3): 280-282.

8. Wang. Z., Piao. J.H., Zhang. F.M., Li. J., Bai. D.F., Yang. J. (2003). Effects of the Semen . Cuscutae on erythrocytemediated immune function in senile mouse model induced by D- gal Heilongjiang.Med.Pharmacy. 26(6): 16-17.

9. Wu, C.Y., Liu, F., Zhang, X.L. (2009). Modern research of Cuscuta chinensis Lam. China. Practical.Med., 4 (14): 243-244.

10. Xia, H.F., Li, X.H. (2012). Progress in pharmacological research of Cuscuta chinensis Lam. J.Modern.Med.Health., 28 (3): 402-403.

11. Ye, M., Yan, Y.N., Ni, X.M., et al. (2001). Study on chemical constituents of the whole plant of Cuscuta chinensis Lam. J.Chinese.Med.Materials, 24 (5): 339-340.

12. Zhang, L., Zhang, P.X., Wang, Z., et al. (2009). Effect of aqueous extract of Cuscuta chinensis Lam. on the activity of myocardial mitochondrial respiratory chain enzyme complexes in aging rat model. Chinese.J.Geronto., 29: 681681.

13. Zhang, P.Q., Tan Y, Zhang C. (2012). Free radical scavenging effect of the extract from Cuscuta chinensis Lam. Central.South.Pharmacy., 10(3): 171-174. 